\title{
Factors that influence the use of the Internet for job-seeking purposes amongst a sample of final-year students in the Eastern Cape province of South Africa
}

\begin{tabular}{|c|c|}
\hline $\begin{array}{l}\text { Authors: } \\
\text { Juliet R. Chiw } \\
\text { Willie T. Chiny } \\
\text { Themba Q. M }\end{array}$ & $\begin{array}{l}\text { ra }{ }^{1} \\
\text { amurindi }{ }^{1} \text { (1) } \\
\text { oli }^{2}\end{array}$ \\
\hline $\begin{array}{l}\text { Affiliations: } \\
\text { 'Department } \\
\text { Management, } \\
\text { Fort Hare, Sol }\end{array}$ & $\begin{array}{l}\text { f Business } \\
\text { University of } \\
\text { th Africa }\end{array}$ \\
\hline $\begin{array}{l}{ }^{2} \text { Department } \\
\text { Psychology, U } \\
\text { Fort Hare, Sou }\end{array}$ & $\begin{array}{l}\text { f Industrial } \\
\text { niversity of } \\
\text { th Africa }\end{array}$ \\
\hline $\begin{array}{l}\text { Correspondin } \\
\text { Willie Chinyan } \\
\text { chinyaz@gma }\end{array}$ & $\begin{array}{l}\text { g author: } \\
\text { nurindi, } \\
\text { il.com }\end{array}$ \\
\hline $\begin{array}{l}\text { Dates: } \\
\text { Received: } 21 \\
\text { Accepted: } 22 \\
\text { Published: } 27\end{array}$ & $\begin{array}{l}\text { an. } 2016 \\
\text { Nov. } 2016 \\
\text { Feb. } 2017\end{array}$ \\
\hline $\begin{array}{l}\text { How to cite th } \\
\text { Chiwara, J.R., } \\
\text { W.T., \& Mjoli, } \\
\text { Factors that ir } \\
\text { of the Interne } \\
\text { seeking purpo } \\
\text { sample of fina } \\
\text { in the Eastern } \\
\text { of South Afric } \\
\text { Human Resou } \\
\text { Management, } \\
\text { Menslikehulp } \\
\text { 15(0), a790. h } \\
10.4102 / \text { sajhr }\end{array}$ & $\begin{array}{l}\text { is article: } \\
\text { Chinyamurindi, } \\
\text { T.Q. (2017). } \\
\text { fluence the use } \\
\text { t for job- } \\
\text { ses amongst a } \\
\text { I-year students } \\
\text { Cape province } \\
\text { a. SA Journal of } \\
\text { rce } \\
\text { SA Tydskrif vir } \\
\text { ronbestuur, } \\
\text { ttps://doi.org/ } \\
\text { m.v15i0.790 }\end{array}$ \\
\hline $\begin{array}{l}\text { Copyright: } \\
\text { ( } 2017 \text {. The } \\
\text { Licensee: AOS } \\
\text { is licensed un } \\
\text { Creative Com! } \\
\text { Attribution Lic }\end{array}$ & $\begin{array}{l}\text { luthors. } \\
\text { IS. This work } \\
\text { der the } \\
\text { nons } \\
\text { ense. }\end{array}$ \\
\hline Read online: & \\
\hline 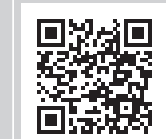 & $\begin{array}{l}\text { Scan this QR } \\
\text { code with your } \\
\text { smart phone or } \\
\text { mobile device } \\
\text { to read online. }\end{array}$ \\
\hline
\end{tabular}

Orientation: Organisations are turning to the Internet in search for talent. A constituency often targeted are those students nearing the end of their tenure of study who are making a transition into the working world. Given this, it is important to understand not only those factors that influence the use of the Internet within the Human Resources (HR) talent search process, but also how such factors relate to actual intent to apply for jobs.

Research purpose: Drawing on the Unified Theory of Acceptance and Use of Technology (UTAUT) model, the study investigates factors that influence the adoption of the Internet for purposes of job seeking.

Motivation for the study: Calls have been made for research that investigates factors that influence the intention to use the Internet to apply for jobs in developing countries such as South Africa.

Research approach, design and method: The study used the quantitative approach (relying on a survey) to test the hypotheses into factors that influence the use of Internet for the purpose of job seeking amongst a sample of 346 prospective job seekers in their final year of study at a South African university.

Main findings: Through correlation and regression analysis, findings reveal a positive relationship to exist between (1) performance expectancy with intention to use the Internet to apply for jobs, (2) effort expectancy with intention to use the Internet to apply for jobs, (3) individual effort expectancy and performance expectancy and (4) individual trust and the intention to use the Internet for job seeking. However, no relationship was found to exist between facilitating conditions and intention to use the Internet for job seeking.

Practical/managerial implications: The findings magnify the role of salient factors in the intention to use the Internet for job-seeking purposes. Efforts from applicants, universities, recruitment agencies and organisations, potentially, have an effect on the intention to use the Internet for job-seeking purposes. Such efforts may enhance the students' online experience and minimise problems that accompany technology adoption for the purposes of recruitment. Findings from this research may help enhance the online recruitment experience both from the end-user and recruiter perspective.

Contribution/value-add: The study contributes to the recruitment literature in three ways: Firstly, UTAUT is shown to be a useful framework to explain final-year, job-seeking students' intention to use the Internet to apply for jobs. Furthermore, the findings illustrate the value of the UTAUT as a model useful in enhancing understanding on intentions. Secondly, the study places focus on the human factor rather than facilitating conditions as important issues regarding intention to use the Internet to apply for a job. Finally, based on these findings, future angles of research that have academic and practitioner implications are proposed.

\section{Introduction}

In South Africa, from a Human Resources Management (HRM) discipline, there is growing empirical focus on the role of technology (e.g. Adams \& De Cock, 2015; Chinyamurindi \& Louw, 2010; Erasmus, Rothmann \& Van Eeden, 2015). One such technology is the Internet and its role on the HRM function, particularly recruitment, as it is tasked with the responsibility of attracting staff into the organisation (O'Meara \& Petzall, 2013). 
The Internet has revolutionised the means by which people communicate, socialise, conduct their businesses and search for jobs (Suvankulov, 2010). This has enabled people to engage in information acquisition and dissemination, networking, business and commerce regardless of their geographic location (Leiner et al., 2013). Access to and use of the Internet appears to be higher in developed countries as compared to developing countries which are usually late adopters when it comes to Information and Communication Technology (ICT) (Pejovic et al., 2012).

However, Internet usage suggests a growing usage in developing countries such as South Africa. Internet World Statistics (2013) highlights that Internet usage in Africa is on the rise, with South Africa ranked number three in the top 10 countries that use the Internet on the continent. Furthermore, Internet usage by individuals was reported to have increased, especially in households as more people access the Internet through their mobile phones (ICT Facts \& Figures, 2013). Given this, it comes as no surprise that South Africa is setting the trend on the African continent in terms of Internet usage by individuals (South Africa Good News, 2013).

This study focuses on investigating factors that influence the use of the Internet for job-seeking prospects amongst a sample of final-year students. The rationale for this study is motivated by three factors. Firstly, the Eastern Cape province is one of the poorest provinces in South Africa (Pejovic et al., 2012), experiencing a high rate of unemployment, especially amongst the youth (Statistics South Africa, 2013). Given that more companies are turning to online recruitment in South Africa (Pavon \& Brown, 2010), understanding the adoption of online recruitment, especially amongst job-seeking youths, may minimise the problem of high unemployment. Second, empirical evidence shows that the success of technological adoption is dependent on its full utilisation (e.g. Chinyamurindi \& Louw, 2010; Chinyamurindi \& Shava, 2015; Hsiao \& Yang, 2011). Paying attention to the factors that influence the adoption of the Internet for job-seeking purposes may enhance not only the experience of using online recruitment portals but also affect intention to use such channels. Finally, given that the study is framed within a job-seeking context, understanding the factors that influence the use of Internet for job-seeking purposes may help employers and recruitment agencies enhance the online job search process, thereby realising potential benefit. Thus, this study has the value of improving an understanding on the factors that influence the use of the Internet for jobseeking purposes especially within a South African context where Internet usage has increased (Shava, Chinyamurindi \& Somdyala, 2016).

This article follows a set structure. First, this research is put into context. Second, the theoretical framework underlying this study is presented, thus leading to the research hypotheses. Third, the research design and methodology section follow. Finally, the results, discussion and a conclusion are presented.

\section{Research purpose and objectives}

The adoption of technology, especially within Higher Education (HE) and the corporate setting, is gaining popularity (Chinyamurindi \& Louw, 2010; Omoniyi \& Quandri, 2013; Shava et al., 2016). This popularity fits within a local and global agenda where the impact of technology in the creation, dissemination and evaluation of knowledge is prioritised (Rienties, Brouwer \& LygoBarker, 2013). Furthermore, technology, especially in rural communities, is argued as important as it meets challenges such as geographical barriers, thus allowing students to connect with the world (Baraghani, 2007). The authors of this article work within the context of a rural university where students rely a lot on the Internet to connect with the world. With regard to job seeking, most of the students on campus rely on the Internet and use online recruitment for the purpose of applying for jobs. This is because of the reality that these students face as they are far from major centres where they can apply for jobs. The researchers' interest was on understanding those factors that influence how final-year job-seeking students use the Internet, particularly for purposes of online recruitment. The overall research question that guided this study was: What factors (given the South African HE context) influence the adoption of the Internet for job-seeking purposes amongst a sample of finalyear students? The next section presents the theoretical background on which this research is based.

\section{Theoretical background}

The Unified Theory of Acceptance and Use of Technology (UTAUT) is adopted as the theoretical lens in this research. The UTAUT framework assesses the factors that influence the adoption of the Internet as a job-seeking tool because it incorporates different constructs from various models on technology adoption which include the Technology Acceptance Model (TAM) (Venkatesh, Morris, Davis \& Davis, 2003). The UTAUT model is argued by Hwang and Schmidt (2011) as a useful tool that can aid in understanding factors that influence technology usage. The UTAUT framework consists of four main constructs: (1) performance expectancy, (2) effort expectancy, (3) social influence and (4) facilitating conditions (Venkatesh et al., 2003). Calls have been made for more studies that investigate the UTAUT framework in various contexts (Dehzad, Hilhorst, De Bie \& Claassen, 2014). The UTAUT framework is believed to have evolved from the TAM to include trust as a construct (Gefen, Karahanna \& Straub, 2003). This is because trust is important when it comes to using the Internet as this affects users' technology acceptance (Pavon \& Brown, 2010). This has led to calls for testing the applicability of the UTAUT as a predictor of human behaviours in various contexts (Ghalandari, 2012). This is a gap this research seeks to fill within a South African context.

\section{Literature review}

Recruitment is a process undertaken by an organisation to attract qualified job seekers suitable for the available job 
vacancies (O'Meara \& Petzall, 2013). Prior to the Internet era, information was difficult to come by (Teoh, Tan \& Chong, 2013). This often made it difficult for the individual to make decisions, especially around job applications. Subsequently, the Internet has greatly helped job seekers acquire information that can positively affect their job and career prospects (Suvankulov, 2010). The reason for this is that the Internet provides information while meeting barriers such as geography, time zones and physical barriers that affect the individual (Chinyamurindi \& Louw, 2010). Thus, within a HE context, students seeking employment can search for jobs, compile company information and even get in touch with potential employers with great ease (Dhamija, 2012). Thus, through online recruitment that affects the individual, potential advantages can be realised for both the student and the recruiter (Dhamija, 2012).

Recruiters can also use the Internet to enable organisations to realise their growth and capacity to attract quality expertise with regards to appropriate levels of knowledge, attitude and aptitude and quantity of $\mathrm{HR}$ at any specified time (O'Meara \& Petzall, 2013). The characteristics that are inherent to the Internet enable employers to contact candidates at any time of the year since having the right person at the right place and at the precise time is crucial for any organisation (Teoh et al., 2013). Many factors influence the adoption of the Internet for job-seeking purposes. Pavon and Brown (2010) identified saliently based on the UTAUT framework: performance expectancy, effort expectancy, trust and facilitating conditions as key factors, especially within a South African context, influencing the behavioural intention and actual usage of the Internet.

\section{Performance expectancy of the Internet}

Performance expectancy (PE) is defined as the beliefs that individuals hold about the technology system, thereby assisting them in attaining a desired output (Venkatesh et al., 2003). Within the context of work, PE can be defined as the belief that job seekers hold about the Internet in aiding the job-seeking process (Dhamija, 2012). This expectation is rooted in the underlying premise that technology serves a utility value (Datta, 2011). It can therefore, either be deemed to be useful or not (Arpaci, 2014). Thus, PE can be positioned as a driving influence towards behavioural intention (Yu, 2012). Conversely, if this driving influence is absent, individual intention to use the Internet for the purpose of job seeking may be impeded (Pavon \& Brown, 2010).

With regard to usage of the Internet for job seeking, PE can be a salient determinant. Coiro and Dobler (2007) argue that student skills, when using the Internet, determine the experience of using the Internet. The absence of such skills may result in not only difficulty for the student but also in a process that is time-consuming, subsequently affecting the intention to use the Internet for job seeking (Kanchanatanee et al., 2014). Therefore, as a precursor to PE in using the Internet for job seeking, students need skills and a motivation in relation to the task before them (Leiner et al., 2013).
Taiwo and Downe (2013) carried out a meta-analysis of empirical research using the UTAUT as a predictive model; findings showed PE to be a strong predictor of the intention to use Information Systems (IS). However, previous studies such as that of Pavon and Brown (2010) only investigated relationships between elements of the UTAUT using skilled job seekers within the South African Information Technology (IT) industry. Calls have been made to be expansive in not only understanding constructs such as PE as part of the UTAUT but also using varying sample groups and contexts (Ghalandari, 2012). This has led to studies showing PE to influence intention to use the Internet in contexts such as the banking sector (Yu, 2012); social media (Gruzd, Staves \& Wilk, 2012) and within a HE context (Brown \& Licker, 2003). Based on this literature, the following was hypothesised:

- Hypothesis 1: Performance expectancy has a positive effect on the intention to use the Internet for job seeking.

\section{Effort expectancy of the Internet}

Effort expectancy (EE) is defined as the extent to which an individual finds the use of technology in general as easy to use with minimal effort (Davis, 1989). Generally, it has been found that easier it is to use technology in any context the more favourable the intention to use the technology (Chu, 2013). Thus, EE extends towards constructs in the TAM and UTAUT such a perceived usefulness and behavioural intention to use (e.g. Chinyamurindi \& Louw, 2010; Chinyamurindi \& Shava, 2015; Ghalandari, 2012; Park, 2010; Shava et al., 2016).

Previous research has found EE to be influenced by factors such as ease of navigation of the Internet (Cober, Brown, Levy, Cober \& Keeping, 2003), aspects of website usability and visibility (Gibson \& Swift, 2011; Musa, Meso \& Mbarika, 2005) and how user friendly the experience is (Tong, 2009). The underlying premise here is that a system or website for job-seeking prospects is easy to use when the user deems it beneficial in relation to the activity and task before the individual (Taiwo \& Downe, 2013). Thus, EE has an indirect effect not only on user adoption of technology but the experience and expectation of using the technology (Zhou, Lu \& Wang, 2010). Based on the literature reviewed, the hypotheses were set as follows:

- Hypothesis 2a: Effort expectancy (ease of use) has a positive effect on the intention to use the Internet for job seeking.

- Hypothesis 2b: Effort expectancy (ease of use) has a positive effect on performance expectancy of the Internet for job seeking.

\section{Trust in the Internet}

Awuah (2012) argues that despite the possibility of a negative experience while using technology, individuals are willing to take a risk and use technology, this being a sign of trust. The issue of trust, thus, emerges as an influencing factor towards the intention to adopt technology. Within the job-seeking 
process, trust plays a part when it comes to submitting personal information, especially over a channel such as the Internet (Bonsòn-Ponte, Carvajal-Trujillo \& EscobarRodríguez, 2015). The trust issue comes in when the individual perceives information submitted online as having the potential of being compromised or being used for a different purpose from the original intent (Jansen, Jansen \& Spink, 2005).

Given the concerns around trust, recruiters using online recruitment need to constantly provide assurance to job seekers (Khan, Awang \& Ghouri, 2013). In this regard, trust becomes an essential component that must be embedded within online recruitment since it affects not only the intention to use but can also be a basis for a competitive advantage (Datta, 2011). In general, users with high levels of trust can reveal more information than those with lower levels of trust (Lin, 2011) and affect levels of adoption of technology (Datta, 2011; Chu, 2013).

An added concern is how recruiters can use technology in making further checks on job seekers outside what has been submitted (Pavon \& Brown, 2010). Thus, trust can exist as determinant of technology usage, as there is no personal relationship between the person submitting the information and the one receiving it (Awuah, 2012; Datta, 2011; EscobarRodriguez \& Carvajal-Trujillo, 2014). Based on the literature presented, the hypothesis is set as follows:

- Hypothesis 3: Trust has a positive effect on the intention to use the Internet for job seeking.

\section{Facilitating conditions of the Internet}

Facilitating conditions (FC) are referred to as the degree to which individuals perceive the availability of infrastructure, whether organisational or technical, for the intended use (Ghalandari, 2012). Facilitating conditions have been seen to have a direct influence on one's behavioural intention to use technology (Venkatesh, Thong \& Xu, 2012). Within a South African context, facilitating conditions have been found to influence technology adoption within the corporate (Chinyamurindi \& Louw, 2010) and HE sectors (Chinyamurindi \& Shava, 2015; Shava et al., 2016). Pavon and Brown (2010) provide a summary of these conditions to include: (1) convenience of Internet access (this could be in terms of the places where one can use the Internet and computers, for example at school, work or home), (2) availability of Internet connectivity and (3) the speed with which one can access the Internet.

Im, Hong and Kang (2011) found that FC, especially those around the Internet access, to vary because of the level of development in the country. In such a case, favourable FC may lead to a greater acceptance of the Internet by users (Lin, 2011; Pavon \& Brown, 2006; Zhou et al., 2010). In the context of this research, it is theorised that FC may affect not only the intention to use the Internet for job seeking but also the ensuing experience.
In developing countries like South Africa, Internet connectivity is slow and sometimes difficult to access because of inadequate information technology infrastructure that facilitates the transmission and distribution of the invisible connection (Kalissa \& Oostdijk, 2006). This has a great effect on the usage of the Internet which, in turn, influences the adoption of the Internet negatively (Musa et al., 2005). Job seekers are consequently restricted to using the Internet because of limited access. To avoid this, availability of infrastructure that accommodates Internet users is recommended (Lin, 2011).

Facilitating conditions are a construct intended to measure user perceptions of the technology environment (Lin, 2011). The authors also note that while it is true with most perceptual constructs, the exact structure of FC may vary slightly across technology studies. The consistent underlying focus, however, is to investigate how an operationalised set of environmental factors facilitates or impedes the use of some technology (Chinyamurindi \& Louw, 2010; Chinyamurindi \& Shava, 2015). For instance, a relationship has been found between facilitating conditions and Internet usage habits (Pavon \& Brown, 2010), and the intention to participate in virtual communities (Lin, 2011) and the use of electronic commerce technologies (Datta, 2011). The hypothesis put forth was:

- Hypothesis 4: Favourable facilitating conditions have a positive effect on Internet usage habits.

These hypothesised relationships are described graphically in Figure 1.

\section{Research design Research approach}

A positivist approach was adopted in this research hinging on the notion that 'causes' determine the 'outcomes' (Creswell, 2014, p. 7). Subsequently, the research adopted a quantitative design in answering the research question. Quantitative studies can help provide description and make inferences around numerical data generated (Creswell, 2014). In gathering the data, the researchers made use of a questionnaire given the advantage this instrument has in being costeffective and allowing the researchers the ability to reach a large number of respondents as used in previous research (Chinyamurindi \& Louw, 2010). A convenience sampling approach was used in this study. This was done to access those respondents who were most accessible and available to take part in the research (Churchill \& Brown, 2010).

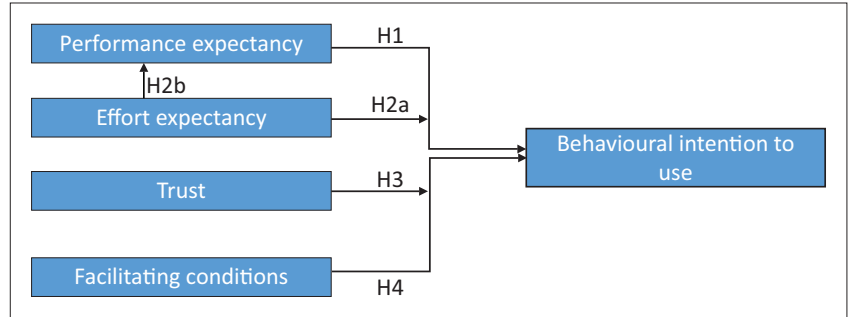

FIGURE 1: Research model. 


\section{Research strategy}

The instrument used a five-point Likert scale (ranging from strongly disagree to strongly agree) and had 22 items. The study hinged on the UTAUT model which is viewed as the prime tool for testing the adoption of technology and has been extensively used in various contexts (e.g. Cruz, Neto, Munoz-Gallego \& Laukkanen, 2010; Gruzd et al., 2012; Van der Heijden, 2003). The questionnaire measured constructs depicted in the theoretical model in Figure 1 concerning the factors that influence the adoption of the Internet for jobseeking purposes (San Martín \& Herrero, 2012).

Students were informed of their rights and that participating in the study was voluntary; ethical consent was shown through signing an ethical agreement form. The researchers also applied for institutional permission to conduct the study and an ethical clearance certificate granted as an outcome of this process. The university where the research was conducted was running a series of job recruitment workshops targeting final-year students within the Faculty of Management and Commerce; these students were looking for employment after their final year of studies. The location of this workshop in one of the university campus buildings was a useful platform to recruit respondents for the research. A total of 400 students were recruited during the 5 -week period when the research was conducted. A total of 346 questionnaires were deemed usable as 54 questionnaires had missing data. This yielded a response rate of $87 \%$. An inclusion criterion was set; respondents had to be registered with the participating university and also in their full-time study within the Faculty of Management and Commerce. A student card was used a useful identifier of students who fit in the parameters of the study.

\section{Reliability test Reliability}

The researchers adhered to the issues of reliability and validity, particularly when collecting, analysing and interpreting the data (Creswell, 2014). The Cronbach's alpha coefficient was used to test for internal consistency (Pallant, 2011). The argument by Santos (1999) was taken into consideration that the higher the Cronbach's alpha coefficient, the more reliable the scale. Previous studies (e.g. Pavon \& Brown, 2010) reported the following in terms of reliability of the scale: (1) FC - 0.76, (2) Trust (TRST) - 0.72, (3) $\mathrm{EE}-0.74$ and (4) PE - 0.84. In this research, the Cronbach's alpha coefficient was calculated for the 22-item questionnaire and found to be 0.78. Furthermore, scales used in this research and their resultant Cronbach's alpha coefficients are shown in Table 1.
Generally, the Cronbach's alpha coefficients for the constructs used in this scale were above the recommended threshold of 0.70 as deemed an acceptable reliability coefficient (Nunnally, 1978). A pilot study was used to pretest the questionnaire amongst a sample of 20 students that were not included in the main study. Suggestions and amendments from this process were taken on board with regard to the main study. These included aspects of simplicity and clarity of questions, including a detailed suggestion of the need for an introductory section of the questionnaire to help students. Furthermore, two lecturers (one lecturing HRM and the other lecturing IS) were also consulted to review a copy of the questionnaire before it was used for data collection. This qualified the instrument for face and content validity.

\section{Data analysis}

To test the hypotheses, a combination of regression and correlation analysis was used. Regression analysis allowed for the estimation of the relationships amongst variables using techniques for modelling and analysing the relationship between the dependent and one or more independent variables (Kothari, 2004). Field (2013) asserts regression analysis as a suitable means of analysis, specifically when there is an outcome variable (dependent variable) and predictor variables (independent variables). As a result, hypotheses tests for the effects of the independent variables (PE, EE, TRST \& FC) to other dependent variables (INT \& IUSEH) were conducted.

To determine the effects of the variables, the Generalised Linear Model (GLM) was used, and Spearman's correlation was used to test the strength between relationships of the variables (Field, 2013). The correlation coefficient is a measure used to evaluate the strength of the relationship between independent and dependent variables (Kothari, 2004). The values of the correlation coefficient range from negative one to positive one. Positive one is considered to be a perfect positive correlation, and this indicates that the relationship between the independent and dependent variable is positive and vice versa (Saunders, Lewis \& Thornhill, 2009).

\section{Research results and findings}

Descriptive statistics about the data are presented in Table 2. The majority $(74 \%)$ of the respondents were female $(n=257)$, while males comprised $26 \%$ of the respondents $(n=89)$. Most of the respondents (66\%) were within the 20-25 age group $(n=228)$. Only 118 students $(34 \%)$ were above 25 years. However, the sample had no respondents who were below 20 years. The majority of the students were Black (African) $(90 \%, n=310$ ), while $10 \%$ of the respondents

TABLE 1: Cronbach's alpha coefficients of instrument used for this research

\begin{tabular}{lccl}
\hline Scale & Items & Cronbach's alpha coefficient & Example item from scale \\
\hline Behavioural intention to use & 3 & 0.867 & 'You intend to use the internet to look for work in the future'. \\
Performance expectancy & 4 & 0.887 & 'The internet is a useful tool for job seeking'. \\
Facilitating conditions & 3 & 0.844 & 'You have the necessary resources to enable you to access the internet'. \\
Effort expectancy & 3 & 0.725 & 'The internet is easy to understand'. \\
\hline
\end{tabular}


were of mixed-race $(n=36)$. Neither Indian nor White students were in the sample.

Concerning the methods of accessing the Internet, Wi-Fi was more popular $(92 \%, n=320)$ than broadband that had only $8 \%$ of the respondents $(n=26)$. Respondents favoured Wi-Fi because it was provided by the university, thus making it the cheapest and most accessible means of accessing the Internet. Respondents were asked how often they accessed the Internet during different time intervals. Responses indicated that $98 \%$ of the respondents used the Internet everyday $(n=340)$, while $8 \%$ of the respondents accessed it once a week $(n=6)$. Table 2 presents the demographic profile of the respondents and their descriptive patterns around Internet usage.

\section{Regression analysis}

Table 3 reveals the results of the regression analysis. With regard to hypothesis 1 , the resulting $F$-value $(F=24.21$; $\mathrm{Pr}>$ $F \leq 0.000)$ showed that the model was highly significant. However, only $25.3 \%(R$-square $=0.253)$ of the variation in intention to use the Internet is being explained by the explanatory variable. The parameter estimates output showed that performance expectancy (estimate $=0.45$; $t$ value $=5.42 ; \operatorname{Pr}>|t| \leq 0.0001)$ has a significant positive effect on intention to use the Internet for job seeking. Hypothesis 1 was, therefore, supported.

Concerning hypothesis $2 \mathrm{a}$ (see Table 3 ), the results are similar to those obtained from the GLM on the first hypothesis. The $F$-value $(F=24.21 ; \operatorname{Pr}>F \leq 0.0001)$ indicated that the model was highly significant. However, only $25.3 \%$ ( $R$-square = 0.253) of the variation in intention to use the Internet is being explained by the effort expectancy variable. There is

TABLE 2: Demographic profile and description of Internet usage.

\begin{tabular}{lcc}
\hline Demographic profile & Frequency & \% \\
\hline Gender & 257 & 74 \\
Female & 89 & 26 \\
Male & & \\
Age & 228 & 66 \\
$20-25$ & 118 & 34 \\
$\quad$ Above 25 & & \\
Ethnicity & 310 & 90 \\
Black (African) & 36 & 10 \\
Mixed race & & \\
Internet access method & 320 & 92 \\
Wi-Fi & 26 & 8 \\
Broadband & & 98 \\
Internet usage habits & 340 & 2 \\
Everyday & 6 & \\
Once a week & &
\end{tabular}

significant evidence, at 5\% significance level, to reject the null hypothesis in favour of the alternative hypothesis (estimate = $0.31 ; t$ value $=2.92 ; \operatorname{Pr}>|t|=0.0041$ ). Effort expectancy (ease of use), therefore, has a positive effect on the intention to use the Internet for job seeking. Based on the results, hypothesis 2a was supported.

With regard to hypothesis $2 \mathrm{~b}$ (see Table 3 ), the resulting $F$-value $(F=9.03 ; \operatorname{Pr}>F=0.0031)$ showed that the model was significant. However, only $5.8 \%(R$-square $=0.058)$ of the variation in performance expectancy is being explained by effort expectancy (ease of use) in the model. The parameter estimates output showed that effort expectancy (ease of use) has a positive significant effect on performance expectancy of the Internet for job seeking (estimate $=0.31 ; t$ value $=3.00$; $\operatorname{Pr}>|t|=0.0031)$. Hypothesis $2 \mathrm{~b}$ was supported.

Concerning hypothesis 3 (see Table 3 ), the resulting F-value $(F=5.46 ; \operatorname{Pr}>F=0.0209)$ showed that the model was significant. However, only $3.6 \%(R$-square $=0.036)$ of the variation in intention to use the Internet was explained by the explanatory variable. The parameter estimates output showed that trust (estimate $=0.21 ; t$ value $=2.34 ; \operatorname{Pr}>|\mathrm{t}|=$ 0.0209 ) had a significant positive effect on intention to use the Internet for job seeking. Hypothesis 3 was, therefore, supported.

Finally, concerning hypothesis 4 (see Table 3 ), the resulting $F$-value $(F=1.69 ; \operatorname{Pr}>F=0.1960)$ showed that the model was not significant. Only $1.1 \%(R$-square $=0.011)$ of the variation in Internet usage habits is being explained by favourable facilitating conditions in the model. The variable estimates output showed that favourable facilitating conditions had no significant effect on Internet usage habits (estimate $=0.24$; $t$ value $=1.30 ; \operatorname{Pr}>|t|=0.1960)$. Based on the results, the hypothesis was not supported.

With regard to correlation analysis, Table 4 presents the results of the analysis conducted. In summary, performance expectancy was correlated with the intention to use the Internet and also the effort expectancy of the Internet for job seeking. Furthermore, effort expectancy and trust had significant correlation with the intention to use the Internet. However, facilitating conditions had no significant correlation with Internet usage habits.

\section{Discussion}

The focus of this study was on understanding those factors that influence how final-year job-seeking students use the Internet, particularly online recruitment, for this purpose.

TABLE 3: Regression analysis results.

\begin{tabular}{|c|c|c|c|c|c|c|c|}
\hline Hypothesis & Relationship & Estimate & $F$-value & $\operatorname{Pr}>F$ & $t$ value & $\operatorname{Pr}>|t|$ & $R$-square \\
\hline 1 & PE-INTENT & 0.45 & 24.21 & $<0.0001$ & 5.42 & $<0.0001$ & 0.253 \\
\hline $2 a$ & EE-INTENT & 0.31 & 24.21 & $<0.0001$ & 2.92 & 0.0041 & 0.253 \\
\hline $2 b$ & EE-PE & 0.31 & 9.03 & 0.0031 & 3.00 & 0.0031 & 0.058 \\
\hline 3 & TRST-INTENT & 0.21 & 5.46 & 0.0209 & 2.34 & 0.0209 & 0.036 \\
\hline 4 & FC-IUSEH & 0.24 & 1.69 & 0.196 & 1.30 & 0.196 & 0.011 \\
\hline
\end{tabular}

$\mathrm{PE}$, performance expectancy; INT, intention to use the Internet; EE, effort expectancy; TRST, trust; FC, facilitating conditions; IUSEH, Internet usage habits. 
TABLE 4: Correlation analysis results.

\begin{tabular}{llll}
\hline Hypothesis & Spearman's correlation & \multicolumn{1}{c}{$\boldsymbol{p}$} & Supported \\
\hline $\mathrm{H} 1$ & 0.43678 & $0.0001^{*}$ & Yes \\
$\mathrm{H} 2 \mathrm{a}$ & 0.33849 & $0.0001^{*}$ & Yes \\
$\mathrm{H} 2 \mathrm{~b}$ & 0.25802 & $0.0017^{*}$ & Yes \\
$\mathrm{H} 3$ & 0.18064 & $0.0291^{*}$ & Yes \\
$\mathrm{H} 4$ & 0.11885 & 0.1531 & No \\
\hline
\end{tabular}

*, significantly correlated at $5 \%$ sig level.

The UTAUT model was the main framework on which the research was based. This section discusses the findings of this work in relation to the extant literature.

Performance expectancy had a significant influence on behavioural intention. The job seekers enjoyed the benefits of using the Internet for job seeking. The benefits include ease in identifying job advertisements and securing employment faster. These benefits will motivate the job seekers to continue using the Internet. These results are consistent with those of previous research (Datta, 2011; Chu, 2013; Taiwo \& Downe, 2013; Venkatesh et al., 2012; Zhou et al., 2010). The results supported the applicability and the reliability of the UTAUT model as a theoretical base, stating that performance expectancy predicts the behavioural intention to use technology (Venkatesh et al., 2003). Attaining desired goals is, therefore, a necessity for job seekers to continue using the Internet for job seeking.

Based on the results of this study, effort expectancy had a significant influence on the behavioural intention to use the Internet. Job seekers will use the Internet because of the ease that comes with using the technology. If the Internet, however, had been difficult to use, job seekers would likely look for easier means for seeking employment. Some job seekers, however, will look for jobs regardless of whether the Internet or websites are easy to use or not. Suggestions were made on how the relationship between effort expectancy and the intention to use the technology can be strengthened by incorporating moderating factors such as user's attitude and computer skills (Awuah, 2012; Venkatesh et al., 2003).

Effort expectancy was reported to have a positive effect on performance expectancy of the Internet for job seeking. These findings were supported by Pavon and Brown (2010) who conducted a similar study of job seeking. Effort expectancy was also reported to be a significant predictor of performance expectancy. Users' perceptions about using mobile banking should be improved by the service providers by providing user-friendly websites, thus reducing effort expectancy and enhancing performance expectancy (Park, 2010). More research should be carried out for a better understanding of the relationship between effort expectancy and performance expectancy.

Users trust the Internet by sharing their personal information and making purchases with their credit cards. This is supported by previous research on the adoption of the Internet for job-seeking purposes which observed that trust had significant effect on intentions to use the Internet for job seeking, and it also had indirect influence on the actual usage of the Internet (Pavon \& Brown, 2010). Resources and infrastructure were not important in determining whether or not job seekers would use the Internet for job seeking. The reason for this was that facilitating conditions (such as the availability of a reliable Internet connection and resources that support this) were reported to have no influence on Internet usage behaviour for job seeking. Despite the fact that job seekers might have the necessary resources and the knowledge on how to use the Internet, this had no significance on their decision to adopt the Internet.

\section{Theoretical implications}

There is more to what really motivates people to use the Internet and in this study, facilitating conditions were not one of them. These results do not support the empirical findings of the UTAUT model, and findings imply that the UTAUT model does not always apply to every context of technology acceptance. There is need to understand other factors that motivate people to use technology. Some websites are easy to use and others are not. The findings suggested that job seekers are likely to use the Internet for job-seeking purposes if it is easy to use. There is a need to learn how to navigate the Internet so that no matter how difficult a website is to navigate, job seekers should be motivated by their need to find jobs. Knowledge of how to use the Internet will make job searches easier.

Since the employers know what influences job seekers to use the Internet for job-seeking purposes, it is the duty of the job seekers to also understand how the employers select the candidates for a certain job. This knowledge will alleviate the job-searching pressure of the individuals as they are aware of some of the expectations of the employers. The literature suggested that online job seeking is more effective when looking for jobs in any geographical location (Leiner et al., 2013). However, traditional methods may appear to be more effective when the job offer is in the local region. Job seekers should, therefore, be able to distinguish between the two methods and be able to choose the method that is more beneficial given the different scenarios.

\section{Practical implications}

Using the Internet for job-seeking purposes might be the easiest, cheapest and fastest way of finding jobs; however, job seekers should not solely rely on online job searches for the following reasons: Firstly, not all organisations advertise jobs on the Internet. Job seekers should therefore also try and incorporate other methods of job seeking which include, but not limited to, using traditional methods such as print media and visiting the organisations in person to submit their curricula vitae. This is in support of the findings of the research that facilitating conditions had no significant effect on the Internet usage habits. By incorporating other methods of job seeking, chances of securing jobs are high, especially when one does not have Internet access or a device to access the Internet. 


\section{Limitations and future research}

The study is limited to the context of tertiary education in South Africa. The study focused on one of the universities in the Eastern Cape province of South Africa, the University of Fort Hare. Perhaps the findings of this research would be different when the research is conducted in another province. For cultural diversity, this study's findings would have been enhanced if a number of universities had participated. Furthermore, because of limited time, data collection of the study was a once-off procedure, and this prohibited the researchers from reporting on trends in job seeking online over time.

This research can be conducted in developed countries so that a comparison of the results can be carried out with the results reported for developing countries. Such comparison would assist in determining whether the socio-economic state of a country plays a role. This comparison could also help determine whether the UTAUT model is applicable in both developed and developing countries. Qualitative research methods can be used to develop a better understanding of what really makes people reluctant to use the Internet. These methods may assist in identifying other factors that influence technology use, and this can lead to the modification of the UTAUT model.

\section{Conclusion}

This study places importance on understanding factors influencing the Internet for the purpose of job seeking amongst a sample of final-year job-seeking students. Such an investigation can be a useful precursor to interventions that help and enhance job seekers as they use the Internet for the purposes of searching for jobs. Furthermore, practitioners such as website designers and recruiters can use the findings of this research in helping design web-based platforms that are user-friendly but can also promote and provide ease of use. Notably, addressing the issues explored in this research can buffer the negative experiences accompanying a complex and emotive activity such as job seeking.

\section{Acknowledgements}

The authors acknowledge the support of the Govan Mbeki Research Development Centre and the Research Niche Area within the Faculty of Management and Commerce at the University of Fort Hare.

\section{Competing interests}

The authors declare that they have no financial or personal relationships that may have inappropriately influenced them in writing this article.

\section{Authors' contributions}

J.R.C. conceptualised the study, collected the data and assisted in thewrite up.W.T.C. assisted in the conceptualisation of the study, collection, analysis of data and write up of the article. T.Q.M. provided advice in the analysis of the data and the final write up.

\section{References}

Adams, S., \& de Kock, F.S. (2015). The role of salient beliefs in graduates' intention to apply. South African Journal of Industrial Psychology, 41(1), 1-11. https://doi. org/10.4102/sajip.v41i1.1223

Arpaci, I. (2015). A comparative study of the effects of cultural differences on the adoption of mobile learning. British Journal of Educational Technology, 46, 699-712. https://doi.org/10.1111/bjet.12160

Awuah, L.J. (2012). An empirical analysis of citizens' acceptance decisions of electronicgovernment services: A modification of the unified theory of acceptance and use of technology (UTAUT) model to include trust as a basis for investigation. PhD dissertation, School of Business \& Technology, Capella University, Minneapolis, MN.

Baraghani, S.N. (2007). Factors influencing the adoption of internet banking. A master's thesis, Department of Business Administration and Social Sciences, Lulea University of Technology, Sweden.

Bonsòn-Ponte, E., Carvajal-Trujillo, E., \& Escobar-Rodríguez, T. (2015). Influence of trust and perceived value on the intention to purchase travel online: Integrating the effects of assurance on trust antecedents. Tourism Management, 47, 286-302. https://doi.org/10.1016/j.tourman.2014.10.009

Brown, I., \& Licker, P. (2003). Exploring differences in Internet adoption and usage between historically advantaged and disadvantaged groups in South Africa. Journal of Global Information Technology Management, 6(4), 6-26. https://doi. org/10.1080/1097198X.2003.10856358

Chinyamurindi, W., \& Shava, H. (2015). An investigation into e-learning acceptance and gender amongst final year students. South African Journal of Information Management, 17(1), 1-9. https://doi.org/10.4102/sajim.v17i1.635

Chinyamurindi, W.T., \& Louw, G.J. (2010). Gender differences in technology acceptance in selected South African companies: Implications for electronic learning. South African Journal of Human Resource Management, 8(1), 1-7. https://doi.org/10.4102/sajhrm.v8i1.204

Chu, K.M. (2013). Motives for participation in Internet innovation intermediary platforms. Information Processing \& Management, 49(4), 945-953. https://doi. org/10.1016/j.ipm.2013.02.006

Churchill, G.A., \& Brown, J.T. (2010). Basic marketing research. South West City, MO: Thompson.

Cober, R.T., Brown, D.J., Levy, P.E., Cober, A.B., \& Keeping, L.M. (2003). Organizational web sites: Web site content and style as determinants of organizational attraction. International Journal of Selection and Assessment, 11, 158-169. https://doi. org/10.1111/1468-2389.00239

Coiro, J., \& Dobler, E. (2007). Exploring the online reading comprehension strategies used by sixth grade skilled readers to search for and locate information on the Internet. Reading Research Quarterly, 42(2), 214-257. https://doi.org/10.1598/ RRQ.42.2.2

Creswell, J.W. (2014). Research design qualitative, quantitative, and mixed methods approaches. (4th edn.). Thousand Oaks, CA: Sage.

Cruz, P., Neto, L.B.F., Munoz-Gallego, P., \& Laukkanen, T. (2010). Mobile banking rollout in emerging markets: Evidence from Brazil. International Journal of Bank Marketing, 28(5), 342-371. https://doi.org/10.1108/02652321011064881

Datta, P. (2011). A preliminary study of ecommerce adoption in developing countries. Information Systems Journal, 21, 3-32. https://doi.org/10.1111/j.1365-2575. 2009.00344.x

Davis, F.D. (1989). Perceived usefulness, perceived ease of use and user acceptance of information technology. MIS Quarterly, 13, 319-340. https://doi.org/10.2307/ 249008

Dehzad, F., Hilhorst, C., De Bie, C., \& Claassen, E. (2014). Adopting health apps, what's hindering doctors and patients? Health, 6, 2204-2217. https://doi.org/10.4236/ health.2014.616256

Dhamija, P. (2012). E-recruitment: A roadmap towards e-human resource management. Researchers World, 3(3), 33-39.

Erasmus, E., Rothmann, S., \& Van Eeden, C. (2015). A structural model of technology acceptance. South African Journal of Industrial Psychology, 41(1), 1-9. https://doi. org/10.4102/sajip.v41i1.1222

Escobar-Rodríguez, T., \& Carvajal-Trujillo, E. (2014). Online purchasing tickets for low cost carriers: An application of the unified theory of acceptance and use of technology (UTAUT) model. Tourism Management, 43, 70-88. https://doi. org/10.1016/j.tourman.2014.01.017

Field, A. (2013). Discovering statistics using IBM SPSS statistics. (3rd edn.). Thousand Oaks, CA: Sage.

Gefen, D., Karahanna, E., \& Straub, D.W. (2003). Trust and TAM in online shopping: An integrated model. MIS Quarterly, 27(1), 51-90.

Ghalandari, K. (2012). The effect of performance expectancy, effort expectancy, social influence and facilitating conditions on acceptance of e-banking services in Iran: The moderating role of age and gender. Middle-East Journal of Scientific Research, 12(6), 801-807.

Gibson, P., \& Swift, J. (2011). E2c: Maximising electronic resources for Cruise recruitment. Journal of Hospitality and Tourism Management, 18(1), 61-69. https://doi.org/10.1375/jhtm.18.1.61

Gruzd, A., Staves, K., \& Wilk, A. (2012). Connected scholars: Examining the role of social media in research practices of faculty using the UTAUT model. Computers in Human Behavior, 28, 2340-2350. https://doi.org/10.1016/ j.chb.2012.07.004 
Hsiao, C.H., \& Yang, C. (2011). The intellectual development of the technology acceptance model: A co-citation analysis, International Journal of Information Management, 31(2), 128-136. https://doi.org/10.1016/j.ijinfomgt.2010.07.003

Hwang, M.I., \& Schmidt, F.L. (2011). Assessing moderating effect in meta-analysis: A re-analysis of top management support studies and suggestions for researchers. European Journal of Information Systems, 20(6), 693-702. https://doi.org/10.1057/ ejis.2011.12

ICT Facts and Figures. (2013). The world in 2013. Retrieved March 12, 2014, from http:// www.itu.int/en/ITU-D/Statistics/Documents/facts/ICTFactsFigures2013-e.pdf

Im, I.L., Hong, S., \& Kang, M.S. (2011). An international comparison of technology adoption- testing the UTAUT model. Information and Management, 48(1), 1-8. https://doi.org/10.1016/j.im.2010.09.001

Internet World Statistics. (2013). Usage and population statistics. Retrieved March 12 2014, from http://www.internetworldstats.com/stats1.htm

Jansen, B.J., Jansen, K.J., \& Spink, A. (2005). Using the web to look for work: Implications for online job seeking and recruiting. Internet Research, 15(1), 49-66. https://doi.org/10.1108/10662240510577068

Kalissa, I., \& Oostdijk, M. (2006). Towards excellence in internet security research for developing countries. Measuring Computing Research Excellence and Vitality, $1(1), 222-229$

Khan, N.R., Awang, M., \& Ghouri, A.M. (2013). Impact of e-recruitment and jobseekers perception on intention to pursue the jobs. Management \& Marketing, 11(1), 47-57.

Kanchanatanee, K., Suwanno, N., \& Jarernvongravab, A. (2014). Factors affecting the intention to use E-marketing of small and medium sized businesses in the three southern border provinces of Thailand. International Journal of Business and southern border provinces of
Social Science, 5(6), 139-144.

Kothari, C.R. (2004). Research methodology: Methods and techniques. (2nd edn.). New Delhi, India: New Age International Publishers.

Leiner, B.M., Cerf, V.G., Clark, D.D., Kahn, R.E., Kleinrock, L., Lynch, D.C. et al., (2013) Brief history of the Internet. Retrieved March 12, 2014, from http://www. internetsociety.org/internet/what-internet/history-internet/brief-historyinternet

Lin, H. (2011). An empirical investigation of mobile banking adoption: The effect of innovation attributes and knowledge- based trust. International Journal of Information Management, 31(3), 252-260. https://doi.org/10.1016/j.ijinfomgt 2010.07.006

Musa, P., Meso, P., \& Mbarika, V. (2005). Toward sustainable adoption of technologies for human development in Sub-Saharan Africa: Precursors, diagnostics and prescriptions. Communications of the Association for Information Systems, 15 prescription

Nunnally, J.C. (1978). Psychometric theory. (2nd edn.). New York: McGraw Hill.

O'Meara, B., \& Petzall, S. (2013). The handbook of strategic recruitment and selection A systems approach. Bingley, United Kingdom: Emerald Group Publishing Limited.

Omoniyi, T., \& Quadri, A.T. (2013). Perceived competence of Nigerian secondary school teachers in the use of Information Communication Technology (ICT) Journal of Education and Practice, 4(10), 157-164.

Pallant, J. (2011). SPSS survival manual: A step by step guide to data analysis using SPSS. (5th edn.). Buckingham, United Kingdom: Open University Press.

Park, N. (2010). Adoption and use of computer based voice over internet protocol phone service: Toward an integrated model. Journal of Communication, 60 40-72. https://doi.org/10.1111/j.1460-2466.2009.01440.x
Pavon, F., \& Brown, I. (2010). Factors influencing the adoption of the World Wide Web for job seeking in South Africa. South Africa Journal of Information Management, 12(1), 1-9.

Pejovic, V., Johnson, D.L., Zhelela, M., Belding, E., Parks, L., \& Stam, G.V. (2012). The bandwidth divide: Obstacles to efficient broadband adoption in rural sub-Saharan Africa. International Journal of Communication, 6, 2467-2491.

Rienties, B., Brouwer, N., \& Lygo-Baker, S. (2013). The effects of online professional development on teachers' beliefs and intentions towards learning facilitation and technology. Teaching and Teacher Education, 29, 122-131. https://doi.org/ 10.1016/j.tate.2012.09.002

San Martín, H., \& Herrero, A. (2012). Influence on the user's psychological factors on the online purchase intention in rural tourism: Integrating innovativeness to the UTAUT framework. Tourism Management, 33, 341-350. https://doi.org/ 10.1016/j.tourman.2011.04.003

Santos, J. (1999). Cronbach's alpha: A tool for assessing the reliability of scales. Journa of Extension, 37(2), 34-36.

Saunders, M., Lewis, P. \& Thornhill, A. (2009). Research methods for business students. (5th edn.). London, England: Pearson Education Limited.

Shava, H., Chinyamurindi, W.T., \& Somdyala, A. (2016). An investigation into the usage of mobile phones among technical and vocational educational and training
students in South Africa. South African Journal of Information Management, 18(1), 1-8. https://doi.org/10.4102/sajim.v18i1.716

South Africa Good News. (2013). 41\% of South Africans use the Internet. Retrieved April 12, 2014, from http://www.sagoodnews.co.za/global_connectedness/ 41_of_south_africans_use_the_internet.html

Statistics South Africa. (2013). Quarterly Labor Force Survey, Statistical Release. Retrieved March 19, 2014, from http://www.statssa.gov.za/publications/P0211/ P02112ndQuarter2013.pdf

Suvankulov, F. (2010). Job Search on the Internet, E-Recruitment, and Labor Market Outcomes. Retrieved February 02, 2016, from http://www.rand.org/content/ $\mathrm{dam} / \mathrm{rand} / \mathrm{pubs} / \mathrm{rgs}$ _dissertations/2010/RAND_RGSD271.pdf

Taiwo, A.A., \& Downe, A. (2013). The theory of user acceptance and use of technology (UTAUT): A meta- analytic review of empirical findings. Journal of Theoretical and Applied Information Technology, 49(1), 48-58.

Teoh, W.M., Tan, S., \& Chong, S.C. (2013). Factors influencing perceptions of university students towards internet recruitment. Asian Academy of Management Journal, 18(1), 123-142.

Tong, D.Y.K. (2009). A study of e-recruitment technology adoption in Malaysia. Industrial Management and Data Systems, 109(2), 281-300. https://doi.org/ 10.1108/02635570910930145

van der Heijden, H. (2003). Factors influencing the usage of websites: The case of a generic portal in the Netherlands. Information and Management, 40, 541-549. https://doi.org/10.1016/S0378-7206(02)00079-4

Venkatesh, V., Morris, M.G., Davis, G.B., \& Davis, F.D. (2003). User acceptance of information technology: Toward a unified view. MIS Quarterly, 27(3), 425-478.

Venkatesh, V., Thong, J.I.L., \& Xu, X. (2012). Consumer acceptance and use of information technology: Extending the unified theory of acceptance and use of technology. MIS Quarterly, 36(1), 157-178.

Yu, C. (2012). Factors affecting individuals to adopt mobile banking: Empirical evidence from the UTAUT model. Journal of Electronic Commerce Research, 13(2), 104-121.

Zhou, T., Lu, Y., \& Wang, B. (2010). Integrating TTF and UTAUT to explain mobile banking user adoption. Computers in Human Behavior, 26, 760-767. https://doi. org/10.1016/j.chb.2010.01.013 